\title{
On the spatial spread of the Rice Water Weevil, Lissorhoptrus oryzophilus Kuschel (Coleoptera: Erirhinidae), in Italy
}

\begin{abstract}
A five year study has been made to establish the spread of the rice water weevil Lissorhoptrus oryzophilus (Coleoptera: Erirhinidae) in Northern Italy. Data obtained with GPS from 2005 throughout 2009 were first georeferenced with SW ArcGis ${ }^{\circledR}$ 9.2, then overlapped and compared to the map of the European environmental landscape based on the interpretation of satellite images (CORINE Land Cover map) and to the hydrographic chart CT10 (Technical Regional map 10000). The analysis of the radial rate of spread per year indicates a deceleration in the expansion from $10.864 \pm 6.801 \mathrm{~km} /$ year in 2005 to $5.318 \pm 1.401 \mathrm{~km} /$ year in 2009 . In five years the weevil has expanded its distribution in nearly all rice paddies in Lombardy and Piedmont, over an area of about 200,000 ha, which correspond to $86 \%$ of the total Italian rice area. Its expansion is thought to follow a type of stratified dispersal, due both to insect adult active dispersal and to accidental movements caused by human transportation.
\end{abstract}

Riassunto - Diffusione in Italia del punteruolo acquatico del riso Lissorhoptrus oryzophilus Kuschel (Coleoptera: Erirhinidae)

Si riportano i risultati di uno studio quinquennale sulla distribuzione spaziale di Lissorhoptrus oryzophilus, il punteruolo acquatico del riso, nel nord Italia. I dati registrati con GPS dal 2005 al 2009 sono stati dapprima georeferenziati con SW ArcGis ${ }^{\circledR} 9.2$, quindi sovrapposti alla mappa europea dell'uso dei suoli basata sull'interpretazione di immagini satellitari (CORINE Land cover map) e sul reticolo idrografico CT10 (mappa tecnica regionale 10000). L'analisi ha evidenziato una progressiva decelerazione nel raggio di espansione dai $10.864 \pm 6.801 \mathrm{~km} / \mathrm{anno}$ nel 2005 ai $5.318 \pm 1.401 \mathrm{~km} /$ anno nel 2009. In cinque anni il fitofago è riuscito a colonizzare quasi tutta l'area risicola di Lombardia e Piemonte, su una superficie di circa 200.000 ha, che corrispondono all' $86 \%$ della superficie risicola italiana. Si pensa che la sua espansione abbia seguito una diffusione stratificata, dovuta allo spostamento attivo dell'insetto e a quello accidentale determinato dai movimenti antropici.

Key words: Italian rice growing areas; settlement; new records; expansion radius. 


\section{INTRODUCTION}

The rice water weevil (RWW), Lissorhoptrus oryzophilus Kuschel, is a polyphagous phytophagous mainly feeding on gramineous and cyperaceous plants (Tindall \& Stout, 2003; Lupi et al., 2009). It is considered one of the most important pests of rice over the world. Damage is caused mainly by larvae, whose activity occurs on rice roots. Crop damage, resulting from RWW larval feeding, reduces plant growth, height, tillering, culm density, and ultimately yield. In extreme cases wind may cause the plant to dislodge and to float (Wu \& Wilson, 1997). Adults are semiaquatic herbivores and they leave longitudinal feeding scars on leaves. Their feeding rarely has economic importance but can be an indicator of the magnitude of consequent larval infestation and damage (Way \& Wallace, 1992).

Originally classified as Lissorhoptrus simplex Say (Webb, 1914), it was described as the new species L. oryzophilus in 1951 (Kuskel, 1951). Both species are native to the United States where they originally fed on gramineous and cyperaceous plants. The collection records for L. oryzophilus given by Kuschel were mostly from southern, central and eastern United States. The RWW was never reported from California before 1959, when it was first discovered in Sacramento Valley (Lange \& Grigarick, 1959).

This species remained confined in North America until 1976 when it spread to Japan (Saito et al., 2005). Thereafter it was detected in China, in Korea, and in India (Lee \& Uhm, 1992; Hix et al., 2000; Chen et al., 2004). The first detection in Europe was in Italy (Caldara et al., 2004). Before this detection, no other species of the genus Lissorhoptrus had been ever detected in Italy (Caldara \& Diotti, 2005). Only Stenopelmus rufinasus Gyllenhal, 1836, belonging to the same tribe of Stenopelmini, imported from America, was formerly present in Italy (Abbazzi \& Osella, 1992). As this finding accidentally occurred during faunistic studies in the litter under woody trees in Ticino Park (Lombardy), it was impossible to acquire information on the pathway of introduction of the insect in Italy.

RWW detection in Italy was really important because the Ticino Park is within a really important rice growing area and Italy is the largest rice producing country in the European Union.

Rice in Italy is mainly cultivated in the North in the Po Valley (Fig.1). About 52\% of the rice area is in Piedmont, mostly in Vercelli and Novara provinces, and about $41 \%$ in Lombardy, for the most part in Pavia and Milan provinces, but rice is also grown in Veneto, Emilia-Romagna and Sardinia.

The dimension of a typical rice farm in Italy is about 48 ha and the average rice yield ranges from 5.0 tons/ha to 6.9 tons/ha, according to the varieties. In 2008, 1,333,000 tons of rice were produced on a surface of 224,198 ha (E.N.R. 2008). In Italy rice is normally water-seeded but in about $25 \%$ of the rice growing area it is dry-seeded and subsequently flooded when seedlings are at the 3-4 leaf stage. In Italy both the traditional Italian type (generally large or short sized, with a soft cooking grain) japonica varieties, and the so-called indica type (long and with slender grains) varieties are grown. Climatic conditions in Italian rice plantations are generally inadequate for authentic indica varieties. 


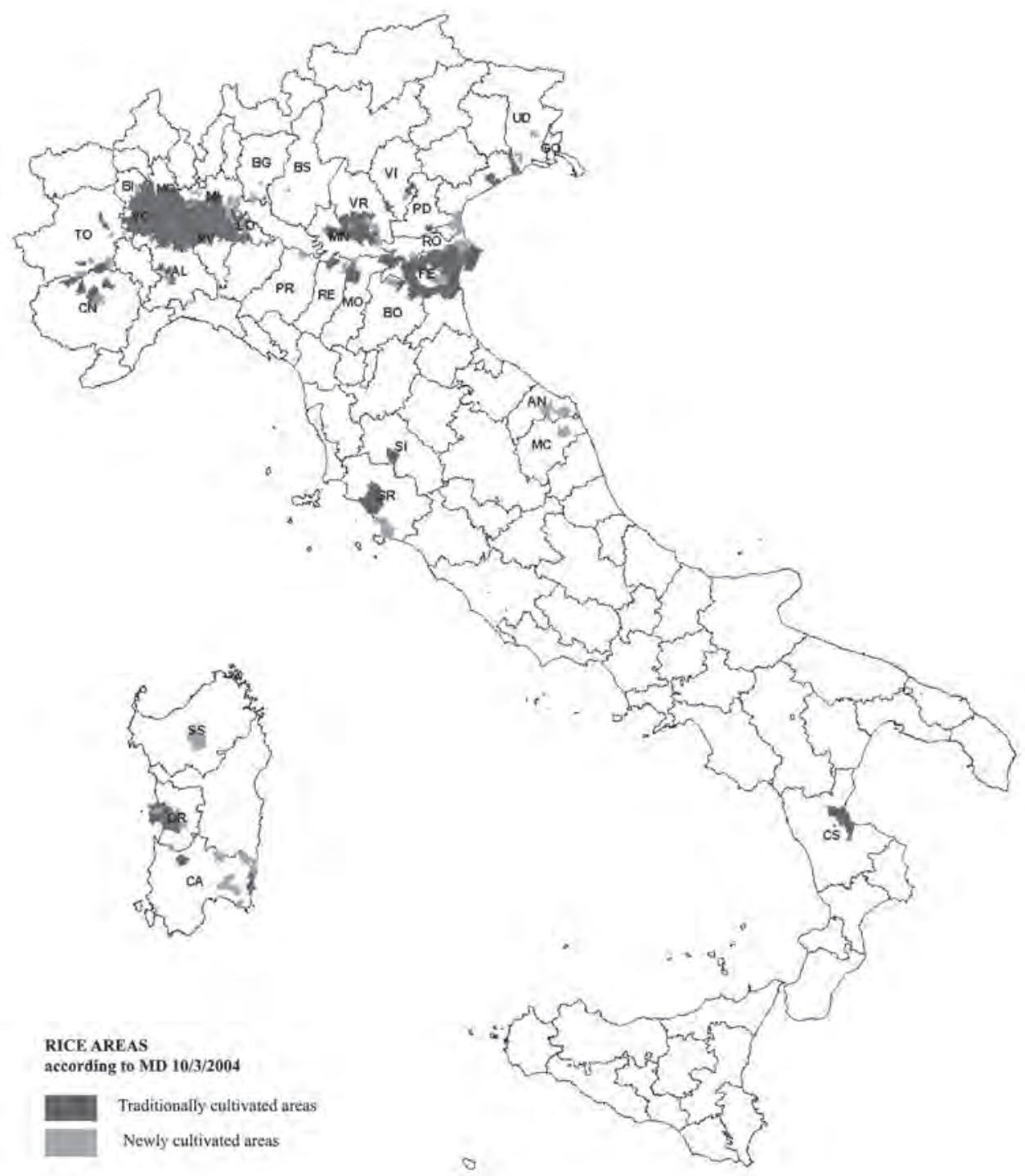

Fig. 1 - Rice field distribution in Italy (cartographic elaboration Paolo Molinari on ISTAT, Italian statistic Institute, data, 2004) 


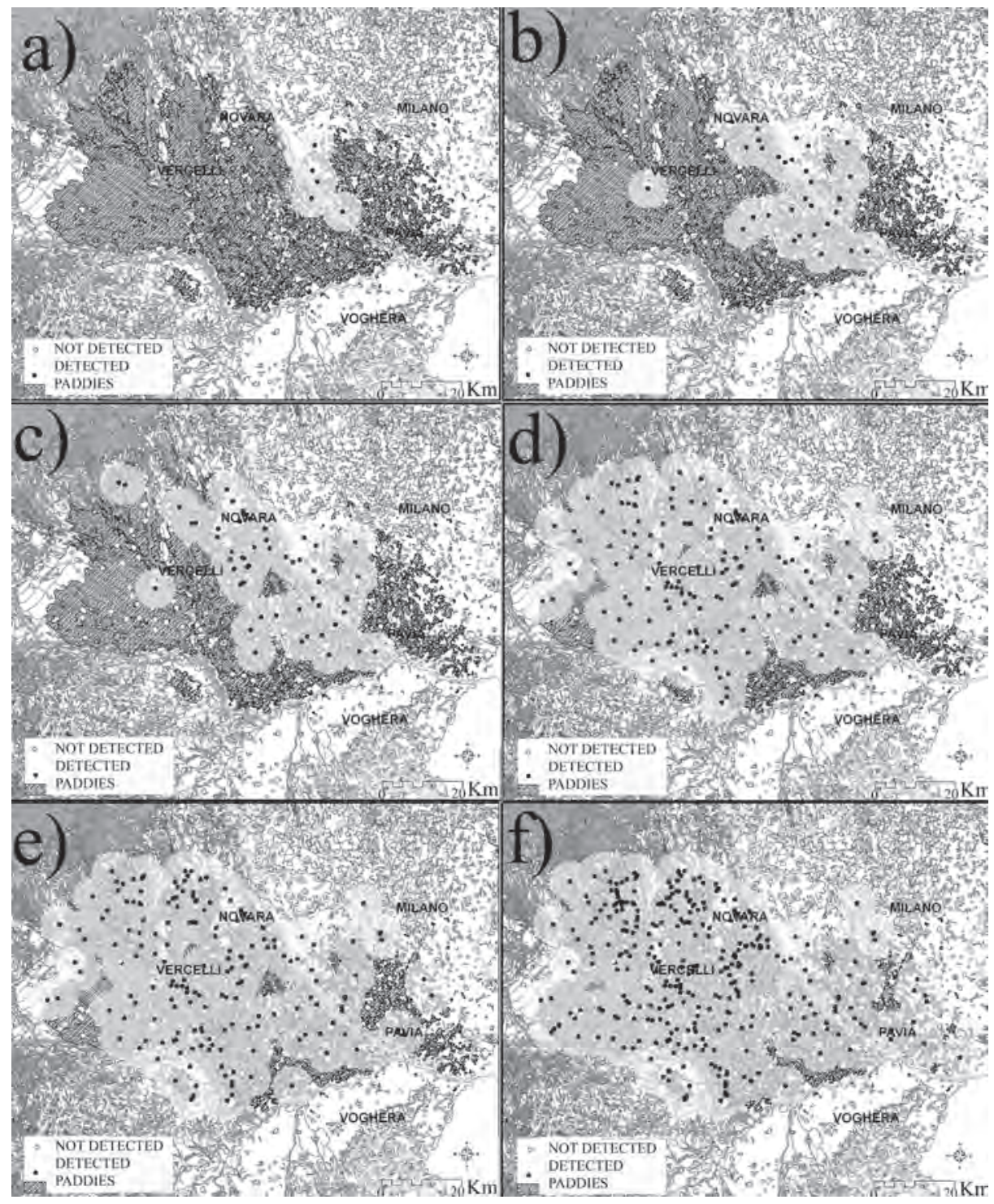

Fig. 2 - SW ArcGis ${ }^{\circledR} 9.2$ representation of Lissorhoptrus oryzophilus spread in rice growing area in Lombardy and Piedmont [2004 (a); 2005 (b); 2006 (c); 2007 (d); 2008 (e); 2009 (f)] 
In some areas, particularly in Vercelli province, rice is grown as a monoculture but can also be grown in rotation with soybean, corn or other cereals.

As rice is cultivated also in many other European countries (Spain, Greece, Portugal, France, Romania, Bulgaria, Hungary) L. oryzophilus was added to EPPO Alert list (EPPO, 2005) where it remained until 2009.

The present survey aimed to establish the capability of settlement of RWW in Italy and its spread.

\section{MATERIALS AND METHODS}

The survey began in March 2005 and was executed throughout 2009.

\section{Study area}

The area of study was the rice growing area in the Po Valley. The main four rice producing provinces (Novara, Vercelli, Pavia, and Milan) are contiguous and are located in this area. They are rich of rivers and canals and are characterized by a continuity of rice fields. Rice is normally water-seeded; except for half of the rice areas in Pavia province. Rice is dry-seeded there to allow the growth of the old traditional varieties, used to cook "risotto" whose plants are very tall (culm length of cv Carnaroli is $120 \mathrm{~cm}$ ) and highly susceptible to lodging.

\section{RWW monitoring procedures}

The methods used to detect the insect in the monitoring process were dependent from the season and, consequently, from the biology of the insect (Bowling, 1972). Overwintering sites were studied in February, in March, in September and in October, collecting the soil and the litter at the base of trees near the rice fields. This material was washed in water and only organic floating material was collected and placed in a Berlese-Tullgren extractor to detect crawling adults. In early spring when the temperature caused the exit of the insect from the litter but rice has not been present yet, adults were searched on weeds with an insect sweep net. After emergence, they were directly searched on rice with direct visual observation From June until July. Larval and pupal presence was checked from the beginning of May until late August by taking root/soil core samples with a metal sampler $(10.0 \mathrm{~cm}$ in diameter by $10.0 \mathrm{~cm}$ deep). Cores were placed into basins with salt water, and soil was washed from roots. Larvae were detected as they floated to the water surface, pupae were searched within rice roots.

Samples of RWW adults, randomly collected in the localities where detected, were carried to laboratory. Specimens were then observed with a stereomicroscope and sexed evaluating externally visible gender-specific characters (Everett \& Newson, 1964).

First detections in 2004 were localized across Ticino river, about $30 \mathrm{~km}$ west of Milan $\left(45^{\circ} 24.17^{\prime} \mathrm{N} 8^{\circ} 55.56^{\prime} \mathrm{E}\right.$; 45 ${ }^{\circ} 19.34^{\prime} \mathrm{N} 8^{\circ} 56.41^{\prime} \mathrm{E}$; $45^{\circ} 20.85^{\prime} \mathrm{N} 8^{\circ} 55.46^{\prime} \mathrm{E}$; $45^{\circ} 17.09^{\prime} \mathrm{N}$ $\left.8^{\circ} 55.30^{\prime} \mathrm{E} ; 4^{\circ} 15.26^{\prime} \mathrm{N} 9^{\circ} 01.27^{\prime} \mathrm{E}\right)$. These localities were at first visited in 2005 , to realize if the insect has settled down and if it was present in rice fields. Further sites were randomly chosen in centrifugal-direction in rice area. 
Each year the localities visited in the previous year were checked again to evaluate the status of the insect and its distribution. New ones were added as appropriate.

The position of each site was georegistered with a GPSMAP ${ }^{\circledR}$ 76S GARMIN (GPS coordinates - map datum WGS84 were used). Information on the insect presence/absence was added.

Data obtained with GPS from 2005 throughout 2009 of the RWW presence in the territory (positive or negative) of Lissorhoptrus oryzophilus were georeferenced with SW ArcGis ${ }^{\circledR}$ 9.2. These data were interpolated in all the territory involved with inverse distance weighted criteria and radius of influence equal to $5 \mathrm{~km}$. Moreover, these data were overlapped and compared to the CORINE Land Cover map and hydrographic chart CT10 (Technical Regional map 10000).

CT10 is a geographical database built up from digitalization of the main element of Technical Regional map at scale 1:10,000.

The "CORINE Land Cover" (European Environment Agency 2009) is the map of the European environmental landscape based on the interpretation of satellite images scale of 1:100,000, in order to provide consistent localized geographical information and make a representation of the territory as a paddy field.

RWW spread was estimated as an increase in range radius over time, where radial rate of expansion ( $r$ ) was calculated as follows

Where

$$
r=\frac{\sum_{i}^{n} d_{i}}{n_{i}}
$$

$r=$ radius of expansion per year; $d=$ distance among new match point in the year (i) and the nearest point in which the insect was detected in the year $(i-1)$; $n=$ number of localities with new detection.

Correlation between radius of expansions and years were analyzed with SPSS $17 \AA$. Pearson's correlation coefficient $(\mathrm{P}<0.01)$.

\section{RESULTS}

A total of 309 localities were surveyed: 67 in 2005; 103 in 2006; 139 in 2007; 156 in 2008 and 309 in 2009 (Table 1).

In 2005, the insect expanded its radius of distribution moving to south and to west in rice paddies, where rice is water seeded and maintained under permanent submersion. It was found in 34 localities, 33 of which in the area surrounding the first detection. There was only one isolated colony in Vercelli province $\left(45^{\circ} 11,10^{\prime} \mathrm{N} 8^{\circ} 18,31^{\prime} \mathrm{E}\right)$.

In 2006, the survey was extended to 103 localities and RWW was detected in 51 sites. It was possible to confirm RWW settlement in all the places in which it was detected in 2005. The insect spreading was limited in the eastern areas, while it was greater in the 
western localities where rice is usually water seeded. Two isolated flash points were also detected $\left(45^{\circ} 23.91^{\prime} \mathrm{N} 8^{\circ} 46.97^{\prime} \mathrm{E}\right.$; 45 $\left.25.00^{\prime} \mathrm{N} 8^{\circ} 46.77^{\prime} \mathrm{E}\right)$.

In 2007 and 2008, 139 and 156 localities were respectively visited. Insect diffusion continued westward in the rice areas. Only few areas remained unsettled especially in the south of Milan where the major presence of dry seeded fields may have affected and postponed the diffusion of the insect. However, four localities gave positive match in this area in 2008.

In 2009 RWW was detected in 267 localities of the 309 visited. Results showed that insect colonization expanded in unsettled areas.

The analysis using Pearson's correlation coefficient indicates a statistically significant negative linear relationship between year and radius of expansions $(r=-0.401$, $\mathrm{p}<0.01)$. The radial rate of spread reached its maximum in 2005 when the mean was $10.864 \pm 6.801 \mathrm{~km}$ and the maximum was of $50 \mathrm{~km}$. Lower values were detected in 2009 when mean radial rate was $5.318 \pm 1.401 \mathrm{~km}$ and maximum radial rate of $15 \mathrm{~km}$ (Tab. 1).

The comparison of RWW distribution with the CORINE Land Cover and CT10 maps allowed the evaluation of the insect diffusion per year in function of the rice paddies and the hydrographic reticulum. While insect presence was strictly related to rice paddies (Fig. 2), it was impossible to find any relationships with the presence of river and canals.

All the specimens collected were parthenogenetic female. No males were ever detected during surveys.

Table 1 - Results of the surveys in the study area over the period of observation

\begin{tabular}{|c|c|c|c|c|c|c|}
\hline Year & $\begin{array}{c}\text { Visited } \\
\text { locations }\end{array}$ & $\begin{array}{c}\text { Positive } \\
\text { match }\end{array}$ & $\begin{array}{c}\text { Negative } \\
\text { match }\end{array}$ & $\begin{array}{c}\text { New } \\
\text { records }\end{array}$ & $\begin{array}{c}\text { Radial rate of } \\
\text { spread } \\
(\mathbf{k m} / \mathbf{y e a r})\end{array}$ & $\begin{array}{c}\text { Maximum } \\
\text { distance } \\
\left(\mathbf{k m}^{2}\right)\end{array}$ \\
\hline 2005 & 67 & 34 & 33 & 29 & $10.864 \pm 6.801$ & 40 \\
\hline 2006 & 103 & 51 & 52 & 17 & $8.750 \pm 7.986$ & 30 \\
\hline 2007 & 139 & 131 & 8 & 80 & $8.532 \pm 5.250$ & 30 \\
\hline 2008 & 156 & 140 & 16 & 9 & $9.333 \pm 5.172$ & 20 \\
\hline 2009 & 309 & 267 & 42 & 127 & $5.318 \pm 1.401$ & 15 \\
\hline
\end{tabular}

(1) Data are expressed as mean \pm stand. dev.

\section{DISCUSSION}

The present study documents the expansion of RWW in one of the most important rice producing areas in Italy. Until RWW detection, there were few arthropod species related to rice cultivation in Italy with few outbreaks and, consequently, damage (Suss et al., 2008). When RWW arrived in Italy, it found an available niche, without competitors or predators.

Considering that three phases are generally recognized in all biological invasions processes (arrival, establishment, and spread) (Williamson, 1996; Liebhold \& Tobin, 
2006), we have to consider that the first one is still unknown for RWW. Besides, since in 2005 the insect was detected in a wide area, we consider that probably RWW had arrived in Italy before 2004. In fact there is typically a period of latency between the arrival of an exotic species and the growth of the population until a level in which it is easy to notice and to spread (Sakai et al., 2001; Liebhold \& Tobin, 2006). We hypothesize that in 2005 the insect has already overcome the initial colonization phase. In fact in the following years the insect diffusions rapidly enlarged into the adjacent rice growing areas. In five years, the weevil has expanded its distribution all over rice paddies in Lombardy and Piedmont, over an area which corresponds to $86 \%$ of the total Italian paddy fields area. RWW diffusion was particularly favoured westwards by the presence of water-seeded fields, and hindered eastwards by the adoption and frequency of different cultivation strategies.

We hypothesize that RWW spread has been facilitated by the presence of a continuity of rice paddies near the area where it was first detected. In fact several theoretical explorations indicate that spread rates are affected by habitat fragmentation (Williamson, 1996; Kamata et al., 2006).

RWW expansion is thought to follow a type of stratified dispersal, in which short range expansion is due to insect adult active dispersal flying, crawling and swimming, while long range expansion is due to accidental movements caused by human transportation (Lockwood et al., 2007). Subsequently the comparison of RWW distribution spreading with rivers and the human route did not allow finding any relationship. However it is important to consider that the rice area in northern Italy is characterized by a dense network of secondary canals, and it is difficult to evaluate their influence on insect movement.

The analysis of the radial rate of spread per year indicates a deceleration in the expansion. This occurrence is common in all exotic pests, in fact after a period of latency there is a subsequent phase of rapid expansion and then a reduction. However RWW radial rate in Italy is quite limited if compared with the insect diffusion in other countries (Liebhold \& Tobin, 2008).

Notwithstanding the quickness of expansion and the area in which the insect had been detected, economic damages had been rarely reported. In 2005 they were only reported in the perimeter zone some paddies in Pavia province (45 $\left.22.74^{\prime} \mathrm{N} ; 8^{\circ} 50.14^{\prime} \mathrm{E}\right)$. In 2006 heavy damage was detected in various farms, dry and water seeded, at the beginning of May 2005. In these farms, the leaf surface of plants localized in the most shaded places, near levees with trees, was completely covered by scars. Among these farms some were dry seeded, but not yet flooded. Although delayed flooding, according to many authors (Rice et al., 1999; Stout et al., 2002) negatively influences and postpones the feeding behaviour and the oviposition of RWW, the particular location of these paddies and the presence of humid areas favoured the insects' settlement. In addition, in 2006, in various farms in the area near the paddies where only slight damage was detected in 2005 $\left(45^{\circ} 22.73^{\prime} \mathrm{N}\right.$; $\left.8^{\circ} 50.14^{\prime} \mathrm{E}\right)$, the yield production was compromised as a consequence of a culm density reduction due to plants dislodging. From 2007 till 2009 damages were limited, and especially in 2009 this was probably due to the adoption of a commercial product (a.p. alfacipermetrine) that has received the extension label for few months. 


\section{ACKNOWLEDGMENTS}

Authors want to thank the technical assistance of Ente Nazionale Risi who helped in the monitoring process, and Prof. Larry Godfrey (UC Davis Department of entomology) for his useful comments.

Work published with a grant of Lombardy Region (Italy) research projects: "Entomological pests in rice fields: biology and control of the rice water weevil and other pests" and "The rice water weevil: biology and biological control"

\section{REFERENCES}

AbbazZi P., Osella G., 1992 - Elenco sistematico-faunistico degli Anthribidae, Rhinomaceridae, Attelabidae, Apionidae, Brentidae, Curculionidae italiani (Insecta, Coleoptera, Curculionoidea). I Parte. Redia, 75: 267-414.

Bowling C. C., 1972 - Note on the biology of rice water weevil, Lissorhoptrus oryzophilus. Ann. Ent. Soc. Am., 65 ( 4): 990-991.

CALDARa R., DiotTi L., 2005 - Notes on Lissorhoptrus, an American weevil genus introduced into Italy, and on Lostianus and Siraton, two Italian "endemic" genera (Coleoptera; Erirhinidae). Boll. Soc. entomol. Ital.137(2): 119-126.

Caldara R., Diotti L., Regalin R., (2004) First record for Europe of the rice water weevil, Lissorhoptrus oryzophilus Kuschel (Coleoptera, Curculionoidea, Erirhinidae). Boll. Zool. Agr. Bachic. ser. II. 36: 165-171.

Chen H., Chen Z., Zhou Y., 2005 - Rice Water Weevil (Coleoptera: Curculionidae) in mainland China: invasion, spread and control. Crop Protection 24: 695-702. DOI: 10.1016/j. cropro.2004.12.005

ENR, 2008 - Superfici coltivate 2008. http://www.enterisi.it/ser_statistiche.jsp Accessed 26 November 2009.

EPPO, 2005 - Reporting Service 2005, No. 1. http://www.invasive.org/library/eppo/Rse-0501. pdf Accessed 26 November 2009.

European Environment Agency, 2009 - CORINE Land Cover [online] http://www.eea.europa.eu/ publications/COR0-landcover Accessed 30 July 2010.

EverETt T.R., NEwSOM L.D., 1964 - External characters for separating the sexes of the rice water weevil, Lissorhoptrus oryzophilus (Coleoptera: Curculionidae). Ann. Soc. Ent. America 57: 514-515.

Hix R.L., Johnson D.T., Bernhardt J.L., 2000 - Swimming behaviour of an aquatic weevil, Lissorhoptrus oryzophilus (Coleoptera: Curculionide). Florida Entomol. 83(3): 316-324.

Kamata N., Liebhold A.M., Quiring D.T., ClanCy K.M. (editors), 2006 - Proceedings IUFRO Kanazawa 2003 International Symposium "Forest Insect Population Dynamics and Host Influences" Kanazawa University, Kanazawa: 176pp.

Kuschel G., 1951 - Revision de Lissorhoptrus Le Conte y generos vecinos de America. Rev. Chil. Ent. 1: 23-74.

LANGE W.H., GRIGARICK W.A., 1959 - Rice Water Weevil Beetle pest in rice growing areas of Southern States discovered in California. Calif. Agric. 13: 10-11. DOI: 10.3733/ca.v013n08p10.

LEE Y.I., UHM K., 1992 - Landing, settling and spreading of the rice water weevil in Korea - In Proc. of workshop: "Establishment, Spread, and Management of the rice water weevil and migratory rice pests in East Asia" Suwon, Korea September 20: 42-56. 
LiebHold A.M., ToBin P.C., 2006 - Growth of newly established alien populations: comparison of North American gypsy moth colonies with invasion theory. Popul. Ecol. 48: 253-262. DOI: $10.1007 / \mathrm{s} 10144-006-0014-4$

LiebHold A.M., Toвin P.C., 2008 - Population ecology of insect invasions and their management. Ann. Rev. Entomol. 53:387-408 DOI: 10.1146/annurev.ento.52.110405.091401

Lockwood J.L., Hopes M.F., MarchetTi M.P., 2007 - Invasion ecology. Blackwell Publishing, Oxford, 312.

Lupi D., Cenghialta C., Colombo M., 2009 - Adult feeding by the rice water weevil Lissorhoptrus oryzophilus on different host plants. Bull. of Insectology 62 (2): 229-236.

Rice W.C., Croughan T.P., Ring D.R.., Muegge M.A., Stout M.J., 1999 - Delayed flood for management of Rice Water Weevil (Coleoptera: Curculionidae). Environ. Entomol. 28 (6) $1130-1135$.

SaIto T., HiRAI K., WAY M.O., 2005 - The rice water weevil, Lissorhoptrus oryzophilus Kuschel (Coleoptera: Curculionidae). Appl. Entomol. Zool., 40 (1): 31-39 DOI:10.1303/aez.2005.31

SaKai AK, Allendorf FW, Holt JS, Lodge DM, Molofsky J, With K.A., Baughman S., Cabin R.J., Cohen J.E., Ellstrand N.C., Mc Cauley D.E., O’Neil P., Parker I.M., Thompson J.N., Weller S.G., 2001 - The population biology of invasive species. Annu. Rev. Ecol. Syst. 32: 305-332 DOI: 10.1146/annurev.ecolsys.32.081501.114037

Stout M.J., Riggio M.R., Zou L., RoberTs R., 2002 - Flooding influences ovipositional and feeding behavior of the Rice Water Weevil (Coleoptera: Curculionidae). J. Agric. Urban entomol. 19 (4) 205-216.

Süss L., LuPI D., SAvoldelli S., 2008 - Parassiti animali. In: Il riso, R. Angelini, Bayer CropScience, Ed. Script, Bologna: 332-353.

Tindall K.V., Stout M.J., 2003 - Use of common weeds of rice as hosts for the rice water weevil (Coleoptera: Curculionidae). Environ. Entomol., 32 (5): 1227-1233.

WAY W.O., Wallace R.G., 1992 - Rice water weevil pest management in the United States with emphasis on the south. In: Proc of workshop: "Establishment, Spread, and Management of the rice water weevil and migratory rice pests in east Asia" Suwon, Korea September 20-24, 1992: 58-83.

WebB J.L., 1914 - Notes on the rice water weevil (Lissorhoptrus simplex Say). J. Econ. Ent. 7: 432-438.

Williamson M., 1996 - Biological Invasions. Chapman and Hall, London. 244 pp.

WU G.W., WILSON L.T., 1997 - Growth and yield response of rice to rice water weevil injury. Environ. Entom. 26 (6): 1191-1201.

Daniela Lupi, Prof.Mario Colombo - DiPSA Università degli Studi di Milano, Via Celoria, 2, I-20133 Milano, Italy.E-mail: daniela.lupi@unimi.it

Giudici Maria Luisa, Villa Bruno, Cenghialta Cesare - Ente Nazionale Risi - Centro Ricerche sul Riso, Strada per Ceretto 4 - I-27030 Castello d'Agogna (PV), Italy. E-mail: crr. patologia@enterisi.it

Passoni Daniele - Politecnico di Milano, DIIAR-Sez. Rilevamento, P.za L. da Vinci, 32 I-20133 Milano.E-mail: daniele.passoni@polimi.it

Accepted 27 August 2010 